\section{Evaluation of the Virucidal Activity of Chemical Disinfectants and Antiseptics: The European Point of View}

To the Editor-In their recent letter to the journal, Ijaz and Rubino ${ }^{1}$ discuss the European Standards (ENs) for the evaluation of the virucidal activity of chemical disinfectants or antiseptics to be used in human medicine (EN 14476:2005) or in industry (EN 13610:1999), and they denounce the ENs as irrelevant. The main argument is based on the observation that the ENs require the use of a quantitative suspension test, which differs from the requirements of the United States, Canadian, and Australian regulatory agencies. ${ }^{1}$ A second important argument is related to the choice of test viruses indicated by the 2 ENs, that is, poliovirus, adenovirus, and bovine parvovirus (EN 14476:2005) and Lactococcus lactis bacteriophages (EN 13610:1999)., ${ }^{2,3}$

ENs for the evaluation of the antimicrobial activity of chemical products are developed by the European Committee for Standardization (CEN), Technical Committee (TC) 216, to provide common principles for the evaluation and authorization of chemical substances in Europe, as required by the European Biocidal Products Directive. ${ }^{4}$ The CEN/TC 216 work program includes phase 1 tests (basic suspension tests to establish the general antimicrobial activity of a given product); phase 2 tests; and phase 3 tests, which describe field tests under practical conditions. Phase 2 tests comprise phase $2 /$ step 1 tests (quantitative suspension tests to establish the activity of products against specific microorganisms under laboratory conditions) and phase 2/step 2 tests (laboratory tests simulating practical conditions, including handwash, handrub, instrument, and surface tests).

Current standards for the evaluation of the virucidal activity represent phase 2/step 1 tests. Norms for phase 2/step 2 tests for surface disinfection in the human medical field are now in preparation. Their development includes the performance of a ring trial, involving several virology laboratories in different countries, with the aim to define the best conditions of a carrier test method to guarantee its robustness, reproducibility, and repeatability. This will be followed by the publication of the corresponding Standard and its adoption by the European Regulatory Authorities.

Various parameters have to be evaluated when preparing such a standard. In particular, the ratio of virus to product is an important factor to be considered for an effective assay. From this point of view, a weakness of the American Society for Testing and Material (ASTM) test E1053-97 (reapproved in 2002$)^{5}$ is the use of a very high disinfectant volume (2 $\mathrm{mL}$ ) compared with the quantity of virus spread on the Petri dish $(0.2 \mathrm{~mL})$. Because of the ratio, this test could be considered more of a suspension test than a carrier test. In comparison, the surface test that CEN/TC 216 is evaluating by means of the ring trial recommends the use of approximately equivalent amounts of virus suspension and product $(0.05$ $\mathrm{mL}$ and $0.1 \mathrm{~mL}$, respectively), which is closer to the reality of surface disinfection.

We agree with Ijaz and Rubino ${ }^{1}$ that vertebrate viruses are important causes of diseases in humans, both in the general community and in the hospital environment. ${ }^{6}$ Virus transfer from contaminated to clean surfaces can be interrupted through the use of microbicides with specific virucidal activity, although not all chemical disinfectants are equally effective. Enveloped viruses can be inactivated by lipid solvents, but those compounds are nearly ineffective against naked viruses. ${ }^{7,8}$ Furthermore, nonenveloped viruses show different levels of sensitivity to chemical substances, picornaviruses being the most resistant in many respects. ${ }^{9}$

In reality, in some specific situations (eg, in surgery departments) the contaminating viruses will be bloodborne (all enveloped viruses), but in the general hospital, the medical departments, or the domestic setting, the presence of more resistant enteric viruses on surfaces cannot be excluded. As a consequence, to be valuable and relevant for health protection when the contaminating virus is not clearly identified, any chemical intended for use as a virucide on surfaces or medical instruments must be effective against all viruses, as demonstrated by its activity against resistant nonenveloped viruses, such as polio virus and adenovirus.

This approach is in line with the requirement of both the infection control community and consumers that products claiming virucidal activity be effective against all known human pathogenic viruses and, therefore, be ready to be used on every occasion and for every need. Conversely, in cases of epidemics in which the virus is clearly identified, the health authorities may advise the population to use less aggressive disinfectants, dependent on the circumstance. For this reason, CEN/TC 216 has decided to choose a candidate virus for its carrier test from among the picornavirus family as the test virus in EN 14476:2005.

On the other hand, chemical substances active against very resistant viruses can sometimes be irritating to human skin. Consequently, CEN/TC 216 is considering the preparation of a specific phase $2 /$ step 2 standard for hygienic hand disinfection that uses test viruses with different sensitivity to disinfectants.

Regarding the use of bacteriophages as test organisms, EN 13610:1999 applies primarily to dairies and the food industry; its scope does not mention household use or professional use. $^{10}$ The main aim of the test is the control of phages in food industries, because bacteriophages can infect bacterial starter cultures, which leads to significant economic loss. For 
this reason, virulent bacteriophages, lytic for starter cultures of Lactococcus lactis that are used for the production of cheese and other fermented milk products, are used as model viruses, and the laboratory test closely simulates the practical conditions of application.

In conclusion, we believe that the ENs for the evaluation of the virucidal activity of chemical disinfectants or antiseptics (EN 14476:2005 and EN 13610:1999) are valuable, and, although they are not perfect, they do have a useful role in helping to defend human health and industrial needs.

\section{ACKNOWLEDGMENTS}

Potential conflicts of interest. All authors report no conflicts of interest relevant to this article.

Graziella Morace, PhD; Kathryn Bellamy, PhD; Pierre Maris, PhD; Jochen Steinmann, PhD

From the Centro per la Ricerca e la Valutazione dei Prodotti Immunobiologici, Istituto Superiore di Sanità, Rome, Italy (G.M.); Unilever Research and Development, Colworth Park, Sharnbrook, Bedfordshire, United Kingdom (K.B.); Agence Française de Securite Sanitaire des Aliments, Fougeres, France (P.M.); and MikroLab, Bremen, Germany (J.S.).

Address reprint requests to Graziella Morace, $\mathrm{PhD}$, Centro per la Ricerca e la Valutazione dei Prodotti Immunobiologici, Istituto Superiore di Sanità, Viale Regina Elena 299, 00161 Rome, Italy (graziella.morace@iss.it). Infect Control Hosp Epidemiol 2009; 30:301-302

(C) 2009 by The Society for Healthcare Epidemiology of America. All rights reserved. 0899-823X/2009/3003-0018\$15.00. DOI: $10.1086 / 595980$

\section{REFERENCES}

1. Ijaz MK, Rubino J. Should test methods for disinfectants use vertebrate viruses dried on carriers to advance virucidal claims? Infect Control Hosp Epidemiol 2008; 29:192-194.

2. European Committee for Standardization. European Standard EN 14476 2005. Chemical disinfectants and antiseptics. Virucidal quantitative suspension test for chemical disinfectants and antiseptics used in human medicine-test method and requirements (phase 2, step 1). 2005.

3. European Committee for Standardization. European Standard EN 13610: 1999. Chemical disinfectants. Quantitative suspension test for the evaluation of virucidal activity against bacteriophages of chemical disinfectants used in food and industrial areas-test method and requirements (phase 2, step 1). 1999.

4. Directive 2000/54/EC of the European Parliament and of the Council of 18 September 2000-17.10.2000 EN Official Journal of the European Communities L 262/21-27.

5. ASTM E1053-97 (2002) Standard Test Method for Efficacy of Virucidal Agents Intended for Inanimate Environmental Surfaces.

6. Sattar A. Microbicides and the environmental control of nosocomial viral infections. J Hosp Infect 2004; 56(Suppl 2):S64-69.

7. Kramer A, Schwebke I, Kampf G. How long do nosocomial pathogens persist on inanimate surfaces? A systematic review. BMC Infect Dis 2006; 6:130.

8. Howie R, Alfa MJ, Coombs K. Survival of enveloped and nonenveloped viruses on surfaces compared with other microorganisms and impact of suboptimal disinfectant exposure. J Hosp Infect 2008; 69:368-376.

9. Sattar SA, Springthorpe VS. Methods of testing the virucidal activity of chemicals. In: Block SS, ed. Disinfection, Sterilization and Preservation. 5th ed. Philadelphia: Lippincott Williams \& Wilkins; 2001:1391-1412.
10. European Committee for Standardization. European Standard EN 14885: 2006. Chemical disinfectants and antiseptics: application of European Standards for chemical disinfectants and antiseptics. 2006.

\section{Reply to Morace et al.}

To the Editor-Morace et al. ${ }^{1}$ have responded to our previous letter to the journal. ${ }^{2}$ They agree with us that vertebrate viruses and not bacteriophages on naturally contaminated environmental hard surfaces pose a danger to public health. However, they disagree with the use of the carrier-based test method for the evaluation of microbicides (at least in the interim period while we wait for the outcome of the ring trial launched under an initiative of the Organization for Economic Cooperation and Development to harmonize test methods for hard-surface microbicides). ${ }^{3}$ They consider the current virucidal suspension test methods of the European Union (EU) to be valuable for the evaluation of microbicides intended for use on environmental hard surfaces. They also believe that microbicides for use on virus-contaminated environmental hard surfaces should possess broad-spectrum virucidal activity.

The test methods for microbicides, including virucides, are currently undergoing substantial revisions in an attempt to make them relevant to a variety of field situations. Efforts are in place for global harmonization of hard-surface test methods. While ideally a microbicide should possess broad-spectrum virucidal activity against both enveloped and hard-toinactivate nonenveloped viruses, ${ }^{4,5}$ not every microbicide on the market is effective against a broad spectrum of viruses, particularly against nonenveloped viruses. Only some of the agents (oxidizers, acids, alcohols, or phenolics), depending on their concentrations, may be effective against nonenveloped viruses..$^{6-8}$ Therefore, consumers should have access both to limited but specific virucidal microbicides and to broadspectrum virucidal microbicides. For example, most of the microbicides on the market would provide a valuable arsenal against severe acute respiratory syndrome (SARS)-associated human coronaviruses (HCoV-SARS) and avian influenza viruses, both of which are enveloped viruses, for both the infection control community and the public at large. Thus, microbicides with limited but specific virucidal activity provide microbicidal value in specific situations and yet don't diminish their potential for sustained use. Although we understand that many active ingredients do not provide broadspectrum activity, we believe it is important for professionals and consumers to have access to broad-spectrum virucidal products, especially because many common illnesses are caused by hard-to-inactivate nonenveloped viruses, such as rhinoviruses and noroviruses.

The current virucidal suspension tests of the EU (BS EN 14476:2005 and EN 13610) $)^{9,10}$ are used to evaluate both dis- 